\title{
Factors Associated with Maternal Health Service Utilization in Cote d'Ivoire: Analysis of the 2011 Ivorian Demographic and Health Survey
}

\author{
Kpebo Djoukou Olga Denise $e^{1,2,3}$, Koumi Mélèdje Marie-Dorothée ${ }^{1,3}$, \\ Agbré Yacé Marie-Laurette ${ }^{1,3}$, Tano-Kamelan Akoua ${ }^{1,3}$, Essis Esme Marie Laure ${ }^{1,3}$, \\ Yavo Williams ${ }^{1}$, Kouassi Dinard ${ }^{1}$ \\ ${ }^{1}$ Maternal and Child Health Unit, National Institute of Public Health, Abidjan, Cote d'Ivoire \\ ${ }^{2}$ Department of Public Health and Biostatistics, Training and Research Unit in Medical Sciences, University Felix Houphouet Boigny, \\ Abidjan, Cote d'Ivoire \\ ${ }^{3}$ Research Department in Reproductive Health of Cote d'Ivoire, National Institute of Public Health, Abidjan, Cote d'Ivoire
}

Email address:

dkpebo@gmail.com (K. D. O. Denise)

\section{To cite this article:}

Kpebo Djoukou Olga Denise, Koumi Mélèdje Marie-Dorothée, Agbré Yacé Marie-Laurette, Tano-Kamelan Akoua, Essis Esme Marie Laure, Yavo Williams, Kouassi Dinard. Factors Associated with Maternal Health Service Utilization in Cote d'Ivoire: Analysis of the 2011 Ivorian Demographic and Health Survey. Science Journal of Public Health. Vol. 7, No. 4, 2019, pp. 115-122. doi: 10.11648/j.sjph.20190704.12

Received: March 5, 2019; Accepted: May 8, 2019; Published: August 8, 2019

\begin{abstract}
Adequate and timely utilization of maternal health services, namely antenatal care and skilled birth attendants, represents a significant intervention for reducing maternal deaths. In Cote d'Ivoire, despite a very high maternal mortality ratio, these services are poorly used. Understanding the factors influencing such poor utilization is critical in designing effective strategies to address this problem. The objective of this study was to analyze factors associated with the use of ANC and Skilled Births Attendants in Cote d'Ivoire. Using data from the 2011 Ivorian Demographic and Health Survey, multivariate logistic regression analysis was conducted to explore determinants of ANC attendance and Skilled Births Attendants at delivery, among 15-49 years old women. Results showed that the coverage of at least 4 ANC and SBA at delivery were low, $43,4 \%$ and $59,1 \%$ respectively. Factors associated with the use of these services were women's and partner's education, household wealth index, media exposure, women's autonomy in health-related decision making and parity. Besides, utilization of at least 4 ANC was also positively associated with the presence of a skilled attendant at birth. These results imply that the determinants of maternal health service utilization are multi-sectoral and thus, need a multi-sectoral approach to tackle it. Policy makers, program managers, and researchers should also explore effective ways of increasing service utilization among less educated women, women from poor households, multipara, and those who are not achieving ANC.
\end{abstract}

Keywords: Antenatal Care, Skilled Delivery Attendant, Maternal Health Service, Determinants, Cote d'Ivoire

\section{Introduction}

Maternal mortality remains a significant public health issue worldwide. In 2015, 303000 women died from pregnancy-related complications [1]. Developing regions account for approximately $99 \%$ of the global maternal deaths, with sub-Saharan Africa alone accounting for roughly $66 \%$, that is about 201,000 maternal deaths [1].

Although several factors may explain such dismal maternal death figure, one of the prominent reasons remains the inadequate access and use of maternal healthcare services, namely antenatal, intrapartum and postnatal health care services [2-6]. Scientific evidence has extensively studied and established the inverse relationship between use of Maternal Health Services (MHS) and the occurrence of maternal deaths [4-9]. For instance, the utilization of a skilled attendant at delivery could avert some estimated 13$33 \%$ of maternal deaths [10]. Women's contact with MHS represents a unique opportunity to provide them with valuable health care promotion and preventive maternal health care interventions, as well as life-saving intrapartum 
and post-partum care [11-14].

Many previous studies revealed that demographic and socio-economic factors such as age, education, household wealth index and exposure to mass media were associated with the use of MHC [2, 15, 16]. Furthermore, parity, perceived quality of care, women level of autonomy, and place of residence are also considered as important factors in determining women's delivery care seeking behavior $[2,12$, $17,18]$.

The maternal mortality rate in Cote d'Ivoire is very high, 645 per 100,000 live births; positioning the country among the 19 countries with the highest MMR worldwide [1]. However, as in most sub-Saharan Africa, the utilization of MHS remains relatively low. According to 2012 Demographic and Health Survey (DHS), the percentage of women with at least one ANC visit by a health professional was $91 \%$, but only $45 \%$ had 4 ANC visits as recommended by the WHO at the time of the survey [19]. The utilization of skilled delivery care is similarly low, and $41 \%$ of women delivered without the assistance of a skilled delivery attendant putting them at high risk of maternal death [19]. Understanding the factors that affect the utilization of these essential maternal health services can help design strategies and develop policies toward the improvement of service utilization in the country; and thereby, will aid in decreasing maternal mortality. Although some studies conducted in Ivory Coast have explored the topic, most of them were small size ones and conducted at a local level, leaving a need for results that can be applied on a large scale [20,21]. With the aim of addressing this research gap, this analysis of a nationally representative survey was conducted to examine the factors associated with the utilization of antenatal care and skilled delivery services. More specifically, the analysis was conducted with the following objectives:

i. To measure the coverage of ANC and SBA utilization in Cote d'Ivoire.

ii. To identify factors associated with the utilization of these services in Cote d'Ivoire.

\section{Methodology}

\subsection{Source of Data and Sample Size}

Data for this analysis were extracted from the 2011-2012 Ivorian DHS, after a formal authorization from MEASUREDHS. Cote d'Ivoire, a French-speaking country located in West Africa, is divided into 11 survey sites, all covered by this survey. The DHS is a community-based cross-sectional study conducted with individuals coming from a nationally representative sample of 10, 413households [19].

A stratified two-stage cluster sampling was used with the aim of obtaining an adequate representation of urban and rural setting as well as that of the eleven regions of the country [19].

The sampling frame consisted of strata or Enumeration Areas (EAs). An EA is a geographic area including a convenient number of dwelling units. On the first stage, 352
EAs were selected, 161 in urban areas and 191 in rural areas, using a probability to proportional size method. Then, on the second stage, based on the place of residence, a fixed number of households per EA was selected, which was 27 in urban areas and 32 in rural areas [19]. In each selected household, all women aged 15-49 were eligible for the survey [19]. Also, in a subsample of 1 out of 2 households, all men aged 15-59 were also eligible for the survey. In total 10060 women and 5677 men were successfully interviewed [19]. The survey collected information on diverse topics, including households socio-demographic characteristics, reproductive health, and maternal and child health. Data was also collected on the birth history in the five years preceding the survey. For the most recent birth, additional data were collected on maternal health care, going from pregnancy to delivery and postnatal care [19].

\subsection{Study Population}

a) Source population: The source population was the total of births that have occurred in the five years preceding the survey.

b) Study population: For each woman who had given at least one birth in the last five years preceding the survey, the DHS made a focus on the most recent birth, by collecting detailed information on pregnancy, delivery, and post-natal health care. In order to ease the analysis, a birth dataset including only the most recent birth was created by merging all the relevant information from all the data collected. In order to minimize recall bias, the analysis was restricted to these last-born children, meaning a total of 4531 births [19].

c) Statistical unit: The most recent birth was considered as the statistical unit.

\subsection{Study Variables}

Data available in the literature were used to inform the selection of the variables included in this analysis.

\subsubsection{Outcome Measure}

For this analysis, we selected two main outcomes to reflect the use of MHS, all coded as binary variables. The first outcome was the number of antenatal care visits during the last pregnancy, categorized as 4 or more ANC (4ANC+, coded 1) vs. less than 4 ANC visits (coded 0). The second outcome was the utilization of skilled delivery attendants, meaning any birth attended either by either a physician, a midwife or a nurse. This outcome was also coded 1 if women received skilled delivery attention and 0 otherwise.

\subsubsection{Exposure Measures}

The potential predictors of utilization of maternal health utilization identified in the dataset were grouped into demographic, socio-economic, accessibility, and reproductive characteristics related variables.

a) Demographic characteristics of mothers: age, education, residence (Urban/Rural), Partner education, region;

b) Socio-economic characteristics: household wealth 
index, exposure to mass media (used as a proxy for measuring the access to health information), parity, number of births in the last 5 years.

c) Accessibility related factors: women involvement in decision-making about the utilization of healthcare services, coded 1 if she was involved and 0 if not, women employment status.

d) Reproductive characteristics: Number of children ever born (parity), number of births in the 5 years preceding the survey.

\subsection{Data Analysis}

Summary statistics including percentage and means ( \pm standard deviation) were used to describe the sociodemographic and background characteristics of the study population (or participants. Bivariate and multivariate logistic regression analyses were then conducted to identify the association between the independent and outcome variables.

At the bivariate level, the chi-square test was first used to identify independent variables, which have an association with the outcomes measures under study. Factors which were significant at a p-value less than 0.25 were included in crude logistic regression models.

Those factors, which were statistically significant in the crude regression models, were added in the multivariable regression models, using a manual stepwise method.

Prior to multiple regression analysis, independent variables were tested for collinearity. Number of births in the past five years was not included in the final model as this variable was highly correlated with number of children ever born (parity). All analyses were conducted using STATA 15.0. Statistical significance was set at $95 \%$ level of significance.

\subsection{Ethical Review}

Considering that DHS data are publicly available, the ethical review had already been obtained from the Institutional Review Board of ICF International, the Center for Disease Control and the Ivorian National Research and Ethics Committee [10].

Detailed information on the study area, study population, organization of the survey, sample design, questionnaires, data collection, data quality, data processing, and ethical issue is published in the full Ivorian Demographic and Health Survey 2011 report [10]. Permission to download the dataset was granted to the authors by MEASURE DHS/ICF International.

\section{Results}

\subsection{Descriptive Characteristics of Respondents}

In total, 5431 women were considered for this analysis. Their background characteristics are summarized in table 1 . The median age of the study subjects was 29 years, and the majority $(68.9 \%)$ was found between the age of 20 to 34 . More than 6 out of 10 women (64.6\%) were from rural areas and had no education (65.7\%). Slightly more than half the respondent $(56.3 \%)$ had no exposure to media.

Regarding wealth index, close to half of the women (48.2\%) belonged to the poorer health while only $31 \%$ were from the richer one. The pattern distribution of partner's education was similar to that of the women, the highest proportion being those with no formal education $(58.6 \%)$. While the majority of women reported that they were working at the time of the survey, only 1 out of $3(29.7 \%)$ had the opportunity to participate in the decision making regarding their use of healthcare service.

Concerning parity, slightly more than 1 out of 3 respondents $(31.2 \%)$ were multiparas ( 5 children and more) whereas $21.2 \%$ were primiparas (first pregnancy). More than one-quarter of the index pregnancies were unwanted at the time of its occurrence. Although a high majority of the women reported at least 1 ANC visit, only $43.4 \%$ completed the four visits as recommended by WHO. About 1 out of 7 women $(68.8 \%)$ attended their first ANC visit only by the second trimester, $13.4 \%$ were very late, between 7 and nine months of gestational age. About 2 out of 5 women (40.2\%) did not use a skilled attendant, but most women (72\%) received PNC in the 48 hours following the delivery.

Table 1. Socio-demographic characteristics of women who had at least one birth in the five years preceding the survey, Cote d'Ivoire 2011.

\begin{tabular}{|c|c|c|}
\hline Socio-demographic characteristics & Frequency & Percentage \\
\hline \multicolumn{3}{|l|}{ Age (years) } \\
\hline $15-19$ & 446 & 8.2 \\
\hline $20-24$ & 1,296 & 23.8 \\
\hline $25-29$ & 1,396 & 25.7 \\
\hline $30-34$ & 1,056 & 19,4 \\
\hline $35-39$ & 727 & 13.4 \\
\hline $40-49$ & 516 & 9.5 \\
\hline Total & 5,431 & 100.0 \\
\hline \multicolumn{3}{|l|}{ Place of residence } \\
\hline Rural & 3,511 & 64.6 \\
\hline Urban & 1,920 & 35.4 \\
\hline Total & 5,431 & 100.0 \\
\hline \multicolumn{3}{|l|}{ Region } \\
\hline Centre & 434 & 8.0 \\
\hline East Centre & 457 & 8.4 \\
\hline North Centre & 537 & 9.9 \\
\hline West Centre & 494 & 9.1 \\
\hline North & 519 & 9.6 \\
\hline North East & 435 & 8.0 \\
\hline North West & 718 & 13.2 \\
\hline West & 502 & 9.2 \\
\hline South without Abidjan & 380 & 7.0 \\
\hline South West & 460 & 8.5 \\
\hline Abidjan & 495 & 9.1 \\
\hline Total & 5,431 & 100.0 \\
\hline \multicolumn{3}{|l|}{ Education level } \\
\hline No education & 3,570 & 65.7 \\
\hline Primary & 1,271 & 23.4 \\
\hline Secondary+ & 590 & 10.9 \\
\hline Total & 5,431 & 100.0 \\
\hline \multicolumn{3}{|l|}{ Wealth Index } \\
\hline Poorest & 1,352 & 24.9 \\
\hline Poor & 1,268 & 23.3 \\
\hline Medium & 1,091 & 20.1 \\
\hline Rich & 1,002 & 18.4 \\
\hline Richest & 718 & 13.2 \\
\hline
\end{tabular}




\begin{tabular}{lll}
\hline Socio-demographic characteristics & Frequency & Percentage \\
\hline Total & 5,431 & 100.0 \\
Partner's level of education & & \\
No education & 2,669 & 58.6 \\
Primary & 952 & 20.9 \\
Secondary & 937 & 20.6 \\
Total (partnered women) & 4558 & 100.0 \\
Decision making for healthcare expenses & & \\
Woman not involved & 3,163 & 70.3 \\
Woman involved & 1,336 & 29.7 \\
Total & 4,499 & 100.0 \\
Respondent currently working & & \\
No & 1,547 & 28.5 \\
Yes & 3,873 & 71.5 \\
Exposure to media & & \\
No & 3,049 & 56.3 \\
Yes & 2,362 & 43,7 \\
Total & 5,411 & 100.0 \\
Parity & & \\
1 & 1,153 & 21.2 \\
2-4 & 2,582 & 47.5 \\
5+ & 1,696 & 31.2 \\
Total & 5431 & 100.0 \\
Number of births in the last 5 years & & \\
1 & 3,374 & 62.1 \\
2+ & 2,057 & 37.9 \\
Total & 5431 & 100.0 \\
Pregnancy wantedness & & \\
No & 1,443 & 26.6 \\
Yes & 3,975 & 73.4 \\
\hline
\end{tabular}

Table 2. Utilization of MHS by delivery by women who had at least one birth in the five years preceding the survey, Cote d'Ivoire, 2011.

\begin{tabular}{|c|c|c|}
\hline Utilization of MHS & Frequency & Percentage \\
\hline \multicolumn{3}{|l|}{ Had at least one $\mathrm{ANC}$} \\
\hline Yes, by a skilled attendant & 4,860 & 89.9 \\
\hline No ANC & 547 & 10.1 \\
\hline Total & 5,407 & 100.0 \\
\hline \multicolumn{3}{|l|}{ Number of ANC } \\
\hline No ANC & 490 & 9.1 \\
\hline Less than 4 ANC & 2,562 & 47.5 \\
\hline $4 \mathrm{ANC}+$ & 2,340 & 43.4 \\
\hline Total & 5,392 & 100,0 \\
\hline \multicolumn{3}{|c|}{ Had at least 4 ANC (4 ANC+) } \\
\hline No & 3,052 & 56.6 \\
\hline Yes & 2,340 & 43.4 \\
\hline Total & 5,392 & 100.0 \\
\hline \multicolumn{3}{|l|}{ Timing of first ANC } \\
\hline Less than 4 months & 1,535 & 31.2 \\
\hline 4 to 6 months & 2,720 & 55.4 \\
\hline 7 to 9 months & 659 & 13.4 \\
\hline Total & 4,914 & 100.0 \\
\hline \multicolumn{3}{|c|}{ Used skilled delivery attendant } \\
\hline No & 2,216 & 40.9 \\
\hline Yes & 3,204 & 59.1 \\
\hline Total & 5420 & 100.0 \\
\hline \multicolumn{3}{|l|}{ Timing PNC } \\
\hline $\mathrm{PNC}$ in $48 \mathrm{~h}$ & 3,912 & 92.4 \\
\hline PNC in 6 weeks & 321 & 7.6 \\
\hline PNC after 6 weeks & 18 & 0.4 \\
\hline Total & 4251 & 100.0 \\
\hline \multicolumn{3}{|l|}{$\mathrm{PNC}$ in $48 \mathrm{~h}$} \\
\hline No & 1,519 & 27.7 \\
\hline Yes & 3,912 & 72.3 \\
\hline Total & 5,431 & 100.0 \\
\hline
\end{tabular}

\subsection{Bivariate Analysis}

The bivariate analysis found a significant association between the majority the independent variables and the two outcomes of interest, use of 4+ ANC and skilled attendance at delivery.

Urban women and those aged 35-39 were more likely to report the utilization of skilled care from pregnancy to delivery. In addition, the utilization of these services was more common among women who had some decision-making power in healthcare related decision and those who were employed. Women who reported exposure to media at least once per week were also more likely to benefit skilled care during pregnancy and delivery. Both indicators of use also increase steadily with education and household socio-economic status. Regarding partnered women, we found that the more educated is the partner, the higher is the proportion of women who used ANC and skilled delivery. In contrast, parity was negatively associated with the outcomes under study, primipara being more prone to use skilled pregnancy and delivery services than multipara.

Table 3. Percentage of women who had at least one birth in the five years preceding the survey who received skilled ANC and delivery service, by background characteristics.

\begin{tabular}{|c|c|c|c|c|}
\hline Characteristics & $\begin{array}{l}\text { Had } 4 \\
\text { ANC \% }\end{array}$ & Chi 2 P & $\begin{array}{l}\text { Skilled } \\
\text { attendant at } \\
\text { delivery } \%\end{array}$ & Chi 2 p \\
\hline \multicolumn{5}{|l|}{ Age (Years) } \\
\hline $15-19$ & 41.1 & 12.77 & 50.6 & 19.2 \\
\hline $20-24$ & 43.8 & 0.026 & 56.6 & 0.002 \\
\hline $25-29$ & 44.7 & & 59.3 & \\
\hline $30-34$ & 43.5 & & 59.6 & \\
\hline $35-39$ & 46.1 & & 58.7 & \\
\hline $40-49$ & 36.9 & & 49.9 & \\
\hline \multicolumn{5}{|l|}{ Place of residence } \\
\hline Urbain & 63.01 & 460.32 & 83.4 & 566,2 \\
\hline Rural & 32.70 & $<0.001$ & 44.7 & $<0.001$ \\
\hline \multicolumn{5}{|l|}{ Region } \\
\hline Centre & 31.71 & 374,79 & 45.4 & 447,2 \\
\hline East Centre & 54.30 & $<0.001$ & 45.4 & $<0.001$ \\
\hline North Centre & 40.41 & & 57.6 & \\
\hline West Centre & 32.59 & & 57.9 & \\
\hline North & 36.80 & & 54.3 & \\
\hline North East & 53.81 & & 65.0 & \\
\hline North West & 26.65 & & 32.3 & \\
\hline West & 47.65 & & 51.3 & \\
\hline South without Abidjan & 53.17 & & 71.3 & \\
\hline South West & 38.56 & & 53.0 & \\
\hline Abidjan & 72.75 & & 93,0 & \\
\hline \multicolumn{5}{|l|}{ Education level } \\
\hline No education & 34.4 & 396.96 & 50.7 & 220.0 \\
\hline Primary & 54.4 & $<0.001$ & 67.4 & $<0.001$ \\
\hline Secondary + & 73.6 & & 87.8 & \\
\hline \multicolumn{5}{|l|}{ Wealth Index } \\
\hline Poorest & 23.4 & 757,7 & 34.0 & 907.0 \\
\hline Poor & 30.9 & $<0.001$ & 40.2 & $<0.001$ \\
\hline Medium & 45.9 & & 63.4 & \\
\hline Rich & 57.8 & & 84.7 & \\
\hline Richest & 79.2 & & 94.5 & \\
\hline \multicolumn{5}{|c|}{ Partner's level of education } \\
\hline No education & 32.2 & 352.1 & 49.9 & 200.8 \\
\hline Primary & 44.5 & $<0.001$ & 58.0 & $<0.001$ \\
\hline Secondary & 67.4 & & 77.8 & \\
\hline \multicolumn{5}{|l|}{ Tertiary } \\
\hline \multicolumn{5}{|c|}{ Women involved in decision making for her healthcare related expenses } \\
\hline Involved & 39.8 & 18,9 & 59.5 & 3.99 \\
\hline
\end{tabular}




\begin{tabular}{lccll}
\hline Characteristics & $\begin{array}{l}\text { Had 4 } \\
\text { ANC \% }\end{array}$ & Chi 2 P & $\begin{array}{l}\text { Skilled } \\
\text { attendant at } \\
\text { delivery \% }\end{array}$ & Chi 2 p \\
\hline $\begin{array}{l}\text { Not involved } \\
\text { Respondent currently }\end{array}$ & 46.8 & $<0.001$ & 56.5 & 0.046 \\
No & 44.5 & 0.9 & 59.14 & 2,37 \\
Yes & 43.0 & 0.340 & 61.7 & 0.124 \\
Exposure to media & & & & \\
No & 31.5 & 401.5 & 45.4 & 353.7 \\
Yes & 58.8 & $<0.001$ & 74.4 & $<0.001$ \\
Parity & & & & \\
1 & 54.2 & 105.6 & 65.5 & 59.6 \\
$2-4$ & 44.3 & $<0.001$ & 60.2 & $<0.001$ \\
$5+$ & 34.8 & & 49.8 & \\
Number of children in the past 5 years & & \\
1 & 34.3 & 110.3 & 62.2 & 60.4 \\
$2+$ & 48.9 & $<0.001$ & 50.3 & $<0.001$ \\
Pregnancy wantedness & & & & \\
No & 46.0 & 5.0 & 60.4 & 4.9 \\
Yes & 42.5 & 0.025 & 56.3 & $<0.027$ \\
\hline
\end{tabular}

\subsection{Multivariate Analysis of Factors Affecting the Use of ANC and Skilled Delivery}

Factors associated with achieving ANC4+ and using skilled birth attendant were examined by multiple logistic regression analysis. After controlling for potential confounding variables, utilization of MHS services was associated with household wealth index, exposure to media, mother's and partner's education, parity, region of residence, and women's participation in decision making regarding use of healthcare services. As compared to poorest women, women in the other $\mathrm{HH}$ wealth index category were two to three times more likely to use maternal health services. The difference was higher for women from the wealthiest $\mathrm{HH}$ who were six times more likely to use skilled pregnancy services than their poorest counterparts $(\mathrm{OR}=6.184,95 \% \mathrm{CI}$ : $4.446,8.602)$. Mothers with some level of education were also more likely to use such services compared to mothers with no education.

Similarly, the more educated the partner, the higher the level of ANC4+ and skilled delivery services. Besides, women who reported media exposure at least once per week were more likely to report use ANC4+ and skilled services at delivery. However, decision making power was only associated with achieving ANC4+ $(\mathrm{AOR}=1.18,95 \% \mathrm{CI}$ : $1.01,1.34)$. Finally, after controlling for confounders, there was a persistent negative relationship only between ANC4+ and parity; women with $2-4$ and women with $5+$ children were less likely to achieve $4 \mathrm{ANC}+(\mathrm{AOR}=0.75,95 \% \mathrm{CI}$ : $0.61,0.92$; $\mathrm{AOR}=0.71,95 \% \mathrm{C}$ I: $0.57,0.88)$. Neither age nor place of residence were associated with the utilization of MHS in the final model.

Table 4. Multivariate logistic regression analysis results for ANC and skilled delivery attendance, Cote d'Ivoire, 2011.

\begin{tabular}{|c|c|c|c|c|}
\hline \multirow{2}{*}{ Variables } & \multicolumn{2}{|l|}{ Had 4 ANC } & \multicolumn{2}{|c|}{ Skilled attendant at delivery } \\
\hline & Adjusted OR & P value & Adjusted OR & P value \\
\hline \multicolumn{5}{|c|}{ Place of residence } \\
\hline Rural & ref & - & ref & \\
\hline Urbain & $1.21[0.98-1.50]$ & 0.075 & $1.11[0.874-1.42]$ & 0.380 \\
\hline \multicolumn{5}{|l|}{ Education level } \\
\hline No education & Ref & - & ref & - \\
\hline Primary & $1.55[1.31-1.84]$ & $<0.001$ & $1.20[0.99-1.46]$ & 0.06 \\
\hline Secondary + & $2.17[1.61-2.94]$ & $<0.001$ & $1.74[1.17-2.60]$ & 0.006 \\
\hline \multicolumn{5}{|l|}{ Wealth Index } \\
\hline Poorest & Ref & & ref & \\
\hline Poor & $1.32[1.08-1.62]$ & $<0.007$ & $1.08[0.89-1.31]$ & 0.44 \\
\hline Medium & $2.39[1.94-2.94]$ & $<0.001$ & $2.30[1.86-2.85]$ & $<0.001$ \\
\hline Rich & $3.14[2.49-3.97]$ & $<0.001$ & $6.20[4.72-8.15]$ & $<0.001$ \\
\hline Richest & $6.18[4.45-8.60]$ & $<0.001$ & $10.98[6.90-17.49]$ & $<0.001$ \\
\hline \multicolumn{5}{|c|}{ Partner's level of education } \\
\hline No education & Ref & - & ref & - \\
\hline Primary & $1.37[1.15-1.63]$ & $<0.001$ & $1.02[0.84-1.24]$ & 0.826 \\
\hline Secondary & $1.66[1.35-2.05]$ & $<0.001$ & $1.18[0.92-1.51]$ & 0.185 \\
\hline Tertiary & $3.13[1.88-5.20]$ & $<0.001$ & $1.26[0.65-2.45]$ & 0.489 \\
\hline \multicolumn{5}{|c|}{ Exposure to media } \\
\hline No & Ref & - & ref & - \\
\hline Yes & $1.53[1.27-1.82]$ & $<0.001$ & $1.22[1.03-1.45]$ & 0.023 \\
\hline \multicolumn{5}{|c|}{ Women involvement in decision making regarding healthcare related expenses } \\
\hline No & Ref & & ref & \\
\hline Yes & $1.18[1.01-1.34]$ & 0.041 & $1.01[0.86-1.19]$ & 0.887 \\
\hline \multicolumn{5}{|l|}{ Parity } \\
\hline 1 & Ref & & - & \\
\hline $2-4$ & $0.75[0.61-0.92]$ & 0.006 & - & - \\
\hline $5+$ & $0.71[1.45-2.72]$ & 0.002 & - & - \\
\hline \multicolumn{5}{|c|}{ Use of ANC during the index pregnancy } \\
\hline No & - & - & ref & - \\
\hline Yes & - & - & $2.31[1.96-2.72]$ & $<0.001$ \\
\hline
\end{tabular}




\section{Discussion}

This study was conducted to assess the coverage of MHS utilization at the national level, and to identify its associated factors. Our results showed that the level of utilization of $4 \mathrm{ANC}+$ and SBA in Cote d'Ivoire is low, at $43,4 \%$ and $59,1 \%$ respectively. Sociodemographics, economic and reproductive health characteristics were the main predictors of maternal healthcare services.

Education of women and their partner were strong predictors of maternal health care utilization for both ANC and SBA services. The results are in agreement with previous studies in other countries [2, 11, 22, 23]. This positive relationship may be explained by the fact that women's education enhances their knowledge and awareness of the importance of maternal healthcare services. They are more likely to have better access to health-related information and increased awareness of services available, resulting in a positive health care-seeking behavior. Education is an opportunity to empower women, providing them with higher confidence and capability to decide to use modern health care services for themselves and their children. They are also more likely to afford the cost of medical healthcare [2].

Expectedly, this study found economic status to be a significant predictor of use of maternal health services. For both indicators, use of maternal services increased steadily with household economic status. Studies elsewhere have also documented a positive relationship between economic status and early antenatal care utilization. [2, 15, 18-20]. In the Ivorian context specifically, this is expected because, while the study was conducted in 2011, the data collected were related to births that occurred in the five years preceding the survey, meaning births from 2005-2010. At that time, access to maternal services in Cote d'Ivoire was mainly depending on out of pocket payment. The deterring effect of such cost of services on the utilization of maternal healthcare has been extensively documented in the literature $[23,24]$. Since then, the country has adopted a free healthcare policy for expectant women and children under five. However, even in such context, one should still expect some inequalities in the use of maternal health services among poorer and richer women. Indeed, Arthur et al. in a similar study conducted in Ghana found that, even though service is provided freely, it may still come with either direct or indirect costs, which are likely to hinder the utilization rates for poorer women. As the authors concluded, there is a need to go beyond the free availability of services and look for additional strategies aiming at improving maternal services accessibility for the poorer [24]. Adopting such strategies is undoubtedly likely to improve the use of MHS among Ivoirian women.

Our study recorded that women who were exposed to mass media at least once a week were more likely to utilize skilled pregnancy and delivery services as compared to those who were not. Studies conducted in Ethiopia and Nigeria found similar results $[2,25]$. Exposure to mass media is considered as a proxy for access to health information. In Cote d'Ivoire, health postcads are frequently diffused through television and radio. Thus, women living in $\mathrm{HH}$ where such devices are available are more likely to be exposed to health-related info, with a subsequent increase in health awareness, as compared to women from no media exposed household.

Decision-making power of women has shown some inconsistent effects on their ability to seek healthcare services. Some studies found an association between women's autonomy and use of MHS [23, 26, 27] while others did not [26]. Such inconsistency is somewhat reflected in our study. Indeed, women' autonomy (as measured by their involvement in healthcare decision making) was positively associated with the utilization of ANC but showed no effect on the utilization of SBA.

Indeed, the lack of autonomy may prevent women from using MHS as needed. On the other hand, decision making involving delivery may appear as a more critical decision as compared to ANC and thus influence by factors other than autonomy. For instance, such a decision as compared to ANC may involve many other decision-makers beyond the women herself. Additionally, the emergency aspect of labor may make it difficult for the woman to have sufficient resources for being fully involved with regards to the choice of the delivery place.

This study has found a negative association between parity and ANC services utilization. The higher the parity, the lesser use of ANC services. However, parity shows no association with the use of SBA. Such a negative relationship is in agreement with the findings of a systematic review of 28 studies on determinants of ANC use as well as that of many other studies $[11,17,22,28]$. Women with a previous pregnancy and birth experience may be reluctant to go again through ANC for a new pregnancy either because they feel more self-confident or because of prior negative experiences using MHS. Meanwhile, primipara may feel more afraid of pregnancy complications or may be more cautious about their pregnancies and sought trained professionals as compared to multipara.

The positive association between ANC attendance and use of SBA is well documented in the literature. This is due to the fact that ANC represents an opportunity for women's exposure to crucial information about the necessary followups from pregnancy to delivery and the safety of skilled delivery attendance. Besides, it allows early detection of obstetric complications that are likely to influence women's decision to have a skilled attendance during childbirth. Interestingly, in this study, ANC was a significant positive determinant of SBA only for those women who attended four or more times as recommended by WHO. The study shows similar results with other studies [2, 11, 22, 25]. It should not be only about achieving some occasional contact with health professionals. Women should be encouraged to complete the required number of $\mathrm{ANC}$, in order to fully reap the benefits of using the continuum of maternal care.

Place of residence has shown an inconsistent relationship with MHS utilization. Some studies found a positive relationship [22, 25, 29] while others did not [30-32]. Age has also shown an inconsistent relationship with MHS service utilization $[2,22,30]$. Our study did not record any association 
between neither place of residence nor age and utilization of maternal health care service. The discrepancies suggest that variation exist by country, and highlight the need to understand critical determinants of service access in a given context in order to tailor effective intervention strategies.

The main strength of this study lies in the national representativeness of the data analyzed. Unlike most studies conducted in Cote d'Ivoire, the finding can be generalized, offering a unique opportunity to inform country-level programs and policies. However, there are some limits worthy of being noted. Even though the most recent births were considered, there could still be some recall bias since the women were asked for events within the last five years prior to the survey. Furthermore, as this is a secondary analysis of existing data, some known predictors of service utilization such as facility-related factors are missing from our analyses.

\section{Conclusion}

The principal associated factors with maternal healthcare utilization include women's and partners' education, household wealth index, exposure to media, the autonomy of decision making and parity. Such results imply that the determinants of maternal health service utilization are multisectoral and thus, need a multi-sectoral approach to tackle it. Policy makers, program managers, and researchers should also explore effective ways of increasing service utilization among less educated women, women from poor households, multipara, and those who are not achieving ANC.

\section{References}

[1] WHO, UNICEF, UNFPA, World Bank Group, United Nations Population Division. Trends in Maternal Mortality: 1990 to 2015. Estimates by WHO, UNICEF, UNFPA, World Bank Group and the United Nations Population Division [Internet]. Available on Disponible sur: https://www.who.int/reproductivehealth/publication/monitorin $\mathrm{g} /$ maternal-mortality-2015/en/

[2] Babalola S, Fatusi A. Determinants of use of maternal health services in Nigeria-looking beyond individual and household factors. BMC pregnancy and childbirth. 2009; 9 (1): 43.

[3] Magadi MA, Agwanda AO, Obare FO. A comparative analysis of the use of maternal health services between teenagers and older mothers in sub-Saharan Africa: evidence from Demographic and Health Surveys (DHS). Social science \& medicine. 2007; 64 (6): 1311-1325.

[4] Yaya S, Uthman OA, Amouzou A, Ekholuenetale M, Bishwajit $\mathrm{G}$. Inequalities in maternal health care utilization in Benin: a population-based cross-sectional study. BMC Pregnancy and Childbirth [Internet]. déc 2018 [cité 4 oct 2018]; 18 (1). Disponible sur: https://bmcpregnancychildbirth.biomedcentral.com/articles/10 .1186/s12884-018-1846-6

[5] PMNCH. The Global Strategy for women's, children, and adolescents' health (2016-2030) [Internet]. Disponible sur: https://www.who.int/pmnch/media/news/2018/ewec-globalstrategy-commitments-2018-report/en
[6] WHO. Strategies toward ending preventable maternal mortality (EPMM) [Internet]. 2015. Disponible sur: https://www.who.int/reproductivehealth/topics/maternalperinatal/epmm/en/

[7] Mpembeni RN, Killewo JZ, Leshabari MT, Massawe SN, Jahn A, Mushi D, et al. Use pattern of maternal health services and determinants of skilled care during delivery in Southern Tanzania: implications for achievement of MDG-5 targets. BMC pregnancy and childbirth. 2007; 7 (1): 29.

[8] Fournier P, Dumont A, Tourigny C, Dunkley G, Dramé S. Improved access to comprehensive emergency obstetric care and its effect on institutional maternal mortality in rural Mali. Bulletin of the World Health Organization. 2009; 87: 30-38.

[9] Buor D, Bream K. An analysis of the determinants of maternal mortality in sub-Saharan Africa. Journal of Women's Health. 2004; 13 (8): 926-938.

[10] Graham WJ, Bell JS, Bullough CH. Can skilled attendance at delivery reduce maternal mortality in developing countries? Safe motherhood strategies: a review of the evidence. 2001;

[11] Birmeta K, Dibaba Y, Woldeyohannes D. Determinants of maternal health care utilization in Holeta town, central Ethiopia. BMC Health Services Research [Internet]. déc 2013 [cité 28 sept 2018];13(1). Disponible sur: $\mathrm{http}: / /$ bmchealthservres.biomedcentral.com/articles/10.1186/1 472-6963-13-256.

[12] Abebe F, Berhane Y, Girma B. Factors associated with home delivery in Bahirdar, Ethiopia: A case control study. BMC Research Notes. 24 nov 2012; 5 (1): 653.

[13] Carroli G, Rooney C, Villar J. How effective is antenatal care in preventing maternal mortality and serious morbidity? An overview of the evidence. Paediatric and Perinatal Epidemiology. janv 2001; 15 (s1): 1-42.

[14] Prata N, Passano P, Sreenivas A, Gerdts CE. Maternal Mortality in Developing Countries: Challenges in Scaling-Up Priority Interventions. Womens Health (Lond Engl). 1 mars 2010; 6 (2): 311-27.

[15] Ahmed S, Creanga AA, Gillespie DG, Tsui AO. Economic Status, Education and Empowerment: Implications for Maternal Health Service Utilization in Developing Countries. Shea BJ, éditeur. PLoS ONE. 23 juin 2010; 5 (6): e11190.

[16] Simkhada B, Teijlingen ER van, Porter M, Simkhada P. Factors affecting the utilization of antenatal care in developing countries: systematic review of the literature. Journal of advanced nursing. 2008; 61 (3): 244-260.

[17] Wilunda C, Quaglio G, Putoto G, Takahashi R, Calia F, Abebe $D$, et al. Determinants of utilization of antenatal care and skilled birth attendant at delivery in South West Shoa Zone, Ethiopia: a cross sectional study. Reprod Health [Internet]. 25 août 2015 [cité 24 oct 2018];12. Disponible sur: https://www.ncbi.nlm.nih.gov/pmc/articles/PMC4592558/

[18] Rurangirwa AA, Mogren I, Nyirazinyoye L, Ntaganira J, Krantz G. Determinants of poor utilization of antenatal care services among recently delivered women in Rwanda; a population-based study. BMC Pregnancy Childbirth. 15 may 2017; 17 (1): 142.

[19] National Institute of Statistics (INS) and ICF International 2012. Demographic and Health Survey and Multiple Indicators Clustered Survey in Ivory Coast 2011-2012. Calverton, Maryland, USA: INS and ICF International. 
[20] Cisse A. Analysis of health care utilization in Côte d'Ivoire. 2011.

[21] Gohou V, Ronsmans C, Kacou L, Yao K, Bohoussou KM, Houphouet B, et al. Responsiveness to life-threatening obstetric emergencies in two hospitals in Abidjan, Côte d'Ivoire. Tropical Medicine \& International Health. 2004; 9(3): 406-415.

[22] Tarekegn SM, Lieberman LS, Giedraitis V. Determinants of maternal health service utilization in Ethiopia: analysis of the 2011 Ethiopian Demographic and Health Survey. BMC Pregnancy and Childbirth [Internet]. déc 2014 [cité 28 sept 2018]; $14 \quad$ (1). Disponible sur: http://bmcpregnancychildbirth.biomedcentral.com/articles/10. 1186/1471-2393-14-161

[23] Ahmed S, Creanga AA, Gillespie DG, Tsui AO. Economic Status, Education and Empowerment: Implications for Maternal Health Service Utilization in Developing Countries. PLOS ONE. 23 juin 2010; 5 (6): e11190.

[24] Arthur E. Wealth and antenatal care use: implications for maternal health care utilization in Ghana. Health Economics Review. 6 août 2012; 2 (1): 14.

[25] Mengesha ZB, Biks GA, Ayele TA, Tessema GA, Koye DN. Determinants of skilled attendance for delivery in Northwest Ethiopia: a community based nested case control study. BMC Public Health. 12 févr 2013; 13 (1): 130.
[26] Bloom SS, Wypij D, Gupta MD. Dimensions of women's autonomy and the influence on maternal health care utilization in a north Indian city. Demography. 2001; 38 (1): 67-78.

[27] Furuta M, Salway S. Women's position within the household as a determinant of maternal health care use in Nepal. International family planning perspectives. 2006; 17-27.

[28] Simkhada B, Teijlingen ER van, Porter M, Simkhada P. Factors affecting the utilization of antenatal care in developing countries: systematic review of the literature. Journal of advanced nursing. 2008; 61 (3): 244-260.

[29] Gabrysch S, Campbell OM. Still too far to walk: literature review of the determinants of delivery service use. BMC pregnancy and childbirth. 2009; 9 (1): 34.

[30] Celik Y, Hotchkiss DR. The socio-economic determinants of maternal health care utilization in Turkey. Social science \& medicine. 2000; 50 (12): 1797-1806.

[31] Navaneetham K, Dharmalingam A. Utilization of maternal health care services in Southern India. Social science \& medicine. 2002; 55 (10): 1849-1869.

[32] Bhatia JC, Cleland J. Determinants of maternal care in a region of South India. 1995. 